\title{
Intelectuais negros \\ e formas de integração nacional
}

Antonio Sér gio A lFredo Guimarães

$\mathrm{E}$

STE ARTIGo trata brevemente de três questões, quais sejam, os diversos modos de integração dos "negros" à sociedade brasileira; a maneira também diversa pela qual se formou a idéia de nação brasileira; e, finalmente, o papel ativo dos intelectuais " negros" na formação do que entendemos por "democracia racial" 1.

0 argumento apresentado, que procura relacionar esses três itens, é o de que a noção de "democracia racial" incorporou idéias elementares dispersas, mas endossadas, ao longo da história brasileira, por negros que foram integrados de diversos modos e que nutriram diferentes identidades nacionais. $\mathrm{O}$ u seja, ainda que intelectuais "brancos", como J oaquim N abuco, Gilberto Freyre ou Arthur Ramos tenham sido proeminentes elaboradores dessas idéias, foram os intelectuais "negros" que, aceitando-as, rearticularam-nas a seu modo, tornando-se responsáveis pela enorme abrangência e capilaridade da doutrina. Do mesmo modo, fossem eles "embranquecidos" ou não, pensassem o povo brasileiro como "mestiço" ou não, essa ideologia foi, durante muito tempo, para esses intelectuais, um importante instrumento de mobilização política dos negros.

\section{D iferentes modos de integração social}

$\mathrm{H}$ á um consenso, na literatura sobre relações raciais² no Brasil, de que a integração dos descendentes de africanos à sociedade brasileira deu-se principalmente pela via do "embranquecimento" ou pelo que Carl Degler (1991) chamou de "válvula de escape do mulato".

"Embranquecimento" pode ser entendido como o processo pelo qual indivíduos negros, principalmente intelectuais, eram sistematicamente assimilados e absorvidos às elites nacionais brasileiras. Florestan Fernandes, por exemplo, diz que:

A filosofia política da solução da questão negra baseou-se sobre o velho padrão da absorção gradual dos indivíduos negros através da seleção e assimilação daqueles que escolhessem se identificar a si mesmos com os círculos dominantes da raça dominante e manifestar completa lealdade aos seus interesses e valores sociais. (Fernandes, 1969, p. 137)

M ais recentemente, Leo Spitzer (1989, p. 102), analisando a saga da família Rebouças, sumarizou o processo de embranquecimento dos negros do seguinte modo: 
I sso significou uma escalada, da extrema pobreza e subordinação baseada no preconceito de cor e na origem escrava, em direção ao domínio de classe e cultura das elites brasileiras predominantemente brancas. Foi geralmente empreendido com intenso esforço pessoal, inteligência e o aproveitamento judicioso das oportunidades para o progresso social e econômico. Tais oportunidades derivavam do fato de que a aceitação social no mundo branco dominante era mais fácil para mulatos e "pessoas de cor" mais claras do que era para os negros. [...] Ademais, era característica da ascensão a conformidade com os valores culturais e os padrões econômicos definidos pelo grupo dominante e pela rejeição de práticas e atitudes consideradas por estes como "inferiores", "atrasadas" e "atavísticas".

O mesmo modelo utilizado por Spitzer para a família R ebouças poderia ser aplicado para muitos outros intelectuais brasileiros que eram considerados pelos seus pares e pela opinião pública como "negros" ou mulatos, como foi o caso, para ficar apenas em al guns, de Alejadinho (1730-1814), L uis G ama (1830-1882), José do Patrocínio (1854-1905); Cruz e Souza (1862-1898); M anuel Q uerino (1851-1923), Lima Barreto (1881-1927) e M ário de Andrade (1893-1945).

O que se chama de embranquecimento, entretanto, não nos deve fechar os olhos para o fato de que a assimilação à cultura luso-brasileira nunca significou uma simples e pura repro dução da estética e da moral política européias, apartadas do meio mulato, ou seja, uma espécie de esquizofrenia racial; ao contrário, esses artistas e intelectuais tidos como "embranquecidos" foram responsáveis pela introdução, na cultura brasileira, de valores estéticos e de idéias híbridas e mestiças, modificando a vida cultural nacional em direção a um estado em que eles e os meios de onde provieram pudessem se sentir mais confortáveis. D e fato, uma estratégia de completo embranquecimento, ou seja, de completa alienação do meio originário, jamais poderia ser bem-sucedida, como nos mostra, aliás muito bem, Spitzer, na sua análise da mobilidade social dos R ebouças. Se foi comum a absorção de pretos e mulatos em famílias e meios sociais brancos e ricos, foi também registrada, nas artes e nos escritos políticos que marcaram o longo caminho da construção da negritude no Brasil, a dolorida experiência de ser negro ou mulato no mundo dos brancos. Senão vejamos.

Comecemos por um dosfundamentos de tal negritude, expresso no poema "O emparedado", de Cruz e Souza (1943):

N ão! N ão! N ão! N ão transporás os pórticos milenários da vasta edificação do mundo, porque atrás de ti e adiante de ti não sei quantas gerações foram acumulando, pedra sobre pedra, pedra sobre pedra, que para aí estás agora o verdadeiro emparedado de uma raça. Se caminhares para a direita baterás e esbarrarás, ansioso, aflito, numa parede horrendamente incomensurável de Egoísmos e Preconceitos! Se caminhares para a esquerda, outra parede, de Ciências e C ríticas, mais alta do que a primeira, te mergulhará profundamente no espanto! 
$\mathrm{N}$ ão é esse mesmo tema do emparedamento psicológico dos negros pela ciência e pelos preconceitos que irá reaparecer mais tarde, nos anos de 1930, na queixa contra o preconceito de cor feita pela imprensa negra de São Paulo? O u expressa na revolta de M ário de Andrade (1938) contra a superstição que acompanha a cor negra desde a Antigüidade: " $\mathrm{N}$ a realidade mais inicial: se o branco renega o negro e o insulta, é por simples e primária superstição?"

$\mathrm{D}$ a artificialidade desse emparedamento se deu conta muito cedo o intelectual negro e a ele reagiu, denunciando o caráter postiço dos brancos. Cito apenas três exemplos: primeiro, o de L uis G ama (1989), que diz do seu pai:

$M$ eu pai, não ouso afirmar que fosse branco, porque tais afirmativas, neste país, constituem grave perigo perante a verdade, no que concerne à melindrosa presunção das cores humanas: era fidalgo; e pertencia a uma das principais famílias da Bahia, de origem portuguesa.

Segundo, o do próprio M ário, que diz mais adiante no artigo já citado: “ 0 que pode consolar o negro] É ver que o branco, o possível branco, o despreza ou insulta exclusivamente por superstição"; terceiro e último, o belíssimo ensaiolibelo de Guerreiro Ramos (1995, p. 222), justamente intitulado "a patologia social do 'branco' brasileiro":

Esta patologia consiste em que, no Brasil, principalmente naquelas regiões [ $\mathrm{N}$ orte e $\mathrm{N}$ ordeste], as pessoas de pigmentação mais clara tendem a manifestar, em sua auto-avaliação estética, um protesto contra si próprias, contra a sua condição étnica objetiva. E é este desequilíbrio na autoestimação, verdadeiramente coletivo no Brasil, que considero patológico. $\mathrm{N}$ a verdade, afeta a brasileiros escuros e claros, mas, para obter alguns resultados terapêuticos, considerei, aqui, especialmente, os brasileiros claros.

Guerreiro complementa a explicação de M ário, mas espicha-lhe o sentido em direção a uma política anticolonialista, ao enxergar a desvalorização estética do negro como produto, não apenas de uma superstição milenar, mas da inculcação de valores coloniais.

O utro elemento central ao modo de se auto-representar como negro na sociedade brasileira é a reivindicação da nação como produto do trabalho negro. A equação entre trabalhadores e negritude traz embutida uma crítica severa aos colonizadores portugueses e um elogio explícito aos africanos como colonizadores. Talvez o modo mais acabado dessa crítica se encontre em M anuel Q uerino:

A idéia de riqueza fácil banira da mente do aventureiro faminto o amor do trabalho, que era considerado uma função degradante. Por mais respeitável que fosse a ocupação era ela desprezada pelos reinós de pretensões afidalgadas. Esta circunstância, porém, favoreceu aos homens de cor nas aplicações mecânicas, e mesmo algumas liberais, cuja aprendizagem valia como um castigo infligido aos humildes, como se fora ocupação infamante. Só a estes era dado trabalhar. (Q uerino, 1980, p. 148) 
Foi o trabalho do negro que aqui sustentou por séculos e sem desfalecimento, a nobreza e a prosperidade do Brasil: foi com o produto do seu trabalho que tivemos as instituições científicas, letras, artes, comércio, indústria etc., competindo-Ihe, portanto, um lugar de destaque, como fator da civilização brasileira. (Q uerino, 1980, p. 156)

M as, a idéia do negro como "parte integrante do povo brasileiro" (1999, p. 23) e do Brasil como "uma pátria que ela [a raça negra] pode, com muito mais direito, chamar sua" (N abuco, 1999, p. 24) vem certamente de antes de 1918, datando da campanha abolicionista. D e fato, o intelectual negro brasileiro forjou e vulgarizou, desde a campanha abolicionista, uma visão positiva da contribuição dos africanos para a construção nacional e para a constituição moral do nosso povo. Tal visão conviveu por várias décadas com uma atitude integracionista politicamente passiva, com a qual os mulatos e negros procuravam demonstrar que a cor era a única diferença entre eles e a elite branca, sem qual quer implicação moral ou cultural.

M as, a partir da terceira década do século XX, um outro modo de integração passou a ganhar importância, no qual a atitude passiva foi abandonada em favor da mobilização política e do cultivo da identidade racial. Esse novo modelo, cujo desenvolvimento pode ser acompanhado pela imprensa negra de São Paulo a partir dos anos de 1920, em jornais como Liberdade e Clarim ${ }^{3}$ se consolida em 1931 com a criação da Frente $\mathrm{N}$ egra Brasileira ${ }^{4}$, movimento social que se transforma em partido político, para ser extinto em 1937, com o Estado N ovo. É bastante provável, como apontam os estudiosos, que dois fatores tenham confluído para a sua emergência: por um lado, um processo de etno-identificação crescente que acompanhou a segunda leva de colonização européia do Brasil no pós-Abolição, depois da chegada maciça de italianos, espanhóis, portugueses, alemães, japoneses, sírios-libaneses e outros europeus, principalmente no Sul e Sudeste do país; e, por outro lado, o processo de politização das diferenças raciais por que passou o mundo ocidental no entreguerras e que, no Brasil, teve no integralismo a sua maior expressão.

No entanto, ainda que a sua origem possa ser atribuída aos fatores mencionados acima, a verdade é que esse novo modo racial de se identificar como brasileiro sobreviveu à derrota do fascismo europeu e se firmou como importante forma de integração do negro na sociedade brasileira, gerando movimentos sociais, dos quais o Teatro Experimental do N egro, no Rio de Janeiro (1944-1964), e o M ovimento N egro U nificado (a parir de 1978) são apenas dois exemplos conspícuos, mas não isolados 5 .

0 que distingue esse modelo do anterior são duas coisas: primeiro, a busca de diálogo e solidariedade coletiva, nacional ou internacionalmente, por meio do pan-africanismo e do afrocentrismo francês e norte-americano; segundo, o fato de que politizam-se a cultura, os interesses materiais e a identidade racial, 
transformados em elementos a um só tempo de contestação, de integração e de mobilidade sociais. Leo Spitzer (1989, p. 181) explica tal modelo, de um ponto de vista sociopsicológico, do seguinte modo:

D esafios diretos à situação marginal, entretanto, estavam presentes num conjunto de respostas de pessoas que mudavam o foco de suas preocupações de soluções individuais em direção a esforços coletivos - do indivíduo para o grupo - e que tentavam transformar seus vínculos somáticos e culturais com as massas subordinadas em instrumento dinâmico de mudança. Tais respostas eram caracteristicamente dadas por pessoas que passavam a ver as barreiras de exclusão que encontravam como impermeáveis e insuperáveis. Percebendo-se a si mesmos como permanentemente bloqueados, estes indivíduos reconsideravam a ideologia assimilacionista que os induzia a se identificar em termos de classe, ou seja, com os "vitoriosos" como eles, e com as pessoas do seu nível educacional, social e econômico. Tendo sido definidos "de fora" como "os outros", internalizaram a identidade que Ihes era imputada, mas rejeitaram a orientação que falhou em Ihes garantir aceitação e reconhecimento nos círculos dominantes.

Alguns autores, todavia, viram-no sob outro prisma. Franklin Frazier (1942) e Charles Wagley (1952), por exemplo, tenderam a considerar a integração dos negros pela via do conflito uma variante regional, presente apenas no Sul do país, onde uma combinação de fatores demográficos e econômicos inibiria a operação do modo tradicionalmente brasileiro de mestiçagem e amalgamação. Reverberavam, assim, as idéias genialmente desenvolvidas por Gilberto Freyre (1940) e mais tarde politizadas por Arthur Ramos (1943), sobre o caráter racialmente democrático da tradicional cultura luso-brasileira. Segundo esse ponto de vista, a arregimentação racial seria produto, tanto da presença minoritária de negros naquela região, como da influência estrangeira, e ganharia corpo, seja por meio de valores aqui expressos pelos novos imigrantes europeus, seja pela inserção internacional do país e a subseqüente propagação, por intermédio das elites, de novos valores e atitudes.

Creio, ao contrário, que seria prudente não perder de vista que tal desenvolvimento se deveu, antes de tudo, às aspirações de novas camadas médias negras por inclusão política e social mais rápida e abrangente, o que, por si só, já inviabilizaria o embranquecimento, modelo mais personalizado e seletivo. Em resumo, acho que também este processo deve ser tratado sob a rubrica do que os sociólogos já chamaram de modernização, ou seja, como subproduto da diversificação e do aumento da complexidade da estrutura e organização sociais, que ocorreu, de fato, mais cedo no Sudeste que no N ordeste do Brasil, mas que não foi, de modo algum, nem cá nem lá, imitativo, superficial ou episódico.

Esse entendimento pode também lançar nova luz sobre o porquê de o modelo competitivo de integração social dos negros se desenvolver, no Brasil, de modo mais lento e relativamente atrasado, se tomarmos como referência o que 
se passou nos Estados $U$ nidos - onde se estabeleceu desde o começo do século $X X$-, e na França d'além-mar, onde, desde a abolição da escravidão nas Antilhas, deu-se um processo de arregimentação de elites negras, conscientes de sua heterogeneidade racial, no quadro ambivalente da unidade do império colonial e da cultura franceses. Sugiro que, a par dos elementos constitucionais a que se referia $N$ abuco (1999, p. 23), e que Gilberto Freyre sintetizou no conceito de mestiçagem, a relativa estagnação econômica e social brasileira, entre a A bolição e os anos de 1930, permitiu que o modelo de integração racial pelo transfor mi smo das elites negras (embranquecimento) se firmasse como hegemônico e restringisse a mobilização coletiva e a arregimentação política como meios de inclusão social. E sta hipótese de trabalho, aliás, encontra-se implícita em alguns dos estudos da chamada "escola paulista" (Bastide, 1974; Fernandes, 1965).

Assim, apenas genealogicamente esses do is modelos podem ser vistos como localizados em regiões e se sucedendo no tempo. U ma vez estabelecidos, eles tendem a se generalizar no espaço político nacional e a se fixar, do ponto de vista de um indivíduo considerado isoladamente, como vias ou escolhas alternativas de mobilidade social, sendo o primeiro de cunho marcadamente individualista e 0 segundo eminentemente coletivista.

H á, entretanto, um terceiro modelo, o qual une integração social, disputa política e heterogeneidade cultural e racial, que se tornou mais visível e nacionalmente aceito a partir dos anos de 1970. R efiro-me a um processo que não atinge grandes intelectuais negros, aqueles que fazem cultura no sentido universalista do termo, mas pequenos intelectuais, propriamente orgânicos como diria G ramsci. Excluídos dos círculos da educação superior e das belas artes, mas tendo internalizado valores modernos, eles procuram transformar a sua cultura de origem ( no sentido relativista que Ihe dá a Antropologia) em cultura negra, ou africana, e a sua diferença coletiva em diversidade cultural.

Seria um erro, entretanto, achar que tal processo não estivesse presente no B rasil desde a A bolição, ou mesmo antes dela, tendo aparecido apenas recentemente. Esse caminho, que foi a um só tempo de criação de alteridade cultural e de mobilidade e integração sociais, desenvolveu-se, sabemos hoje (Reis, 1999), em íntima relação, de negociação e conflito, com as elites dirigentes ${ }^{6}$. 0 desenvolvimento da religião dos orixás, na Bahia e em outras partes do Brasil, por exemplo, deu-se num contexto que envolveu não apenas repressão e resistência, mas também respaldo e cumplicidade de autoridades políticas e intelectuais.

Como modelo, o processo assemelha-se àquele do embranquecimento pelo fato de que os aliados históricos desses negros, na sua busca de distinção cultural e de reconhecimento social, foram também os brancos (autoridades estatais e intelectuais). $M$ as se distingue dele e se aproxima do modelo da arregimentação política por enfatizar a distinção cultural ou racial.

Sendo concomitantes no tempo, os três modelos apresentados acima podem ser considerados como alternativos e, logo, passíveis de escolhas individuais. M as, 
há que se levar em conta que configurações so ciais (de classe) e geográficas (regionais), e não apenas familiares e psicológicas, limitam e restringem tais escolhas.

Assim, é verdade que, em São Paulo, em grande parte devido à vontade de suas lideranças políticas, desenvolveu-se cedo uma classe operária com cultura e identidade próprias que suplantou numericamente a antiga classe de escravos, homens-livres e ingênuos, deslocando e marginalizando expressões do que poderia vir a ser uma cultura negra. $\mathrm{N}$ a Bahia, ao contrário, a industrialização mais lenta e o peso demográfico dos descendentes de africanos, combinados com a precariedade do sistema de educação pública, parecem ter contribuído para que muitos pretos e mulatos optassem por preservar suas origens culturais e utilizá-las como meio de inclusão na sociedade dos brancos (Butler, 1998).

$M$ as, a integração dos negros à nação brasileira não foi um processo simples apenas porque houve vários modos de fazê-lo. Essa nação foi também imaginada de várias maneiras e, ademais, a identidade nacional foi uma resposta a perguntas diferentes; para uns, tratava-se de saber quem era o povo brasileiro; para outros, o que era o Brasil.

Por isso, para concluir meu argumento, apresento a seguir, sem, entretanto, desenvolvê-la, uma taxonomia de respostas que inspiraram e ainda inspiram possíveis matrizes para ideologias nacionais.

A primeira resposta à pergunta "o que é o B rasil?" é curta e peremptória: 0 Brasil é um país branco. 0 trecho que reproduzo abaixo de um importante intelectual paulista dos anos de 1940 é um excelente exemplo dessa matriz:

U ma coisa porém existe e existirá com absoluta nitidez: a deliberação marcada pelo consenso unânime dos brasileiros lúcidos: o Brasil quer ser um país branco e não um país negro. $\mathrm{N}$ ão vem aqui agora o estudo ou a pesquisa destinada a saber se o negro é intelectual ou moralmente inferior ao branco, ou ao índio, se o branco ou o índio são menos primitivos ou mais adiantados do que o negro. 0 que prevalece é a decisão brasileira de ser um país branco e mais nada. E este propósito, sólido, inabalável, existe, é a realidade. O ra, assim sendo, há duas maneiras, para os países brancos, que receberam um contingente grande de negros, de conservarem-se brancos. $\mathrm{O}$ u têm que adotar o méto do cruel e desumano, sociologicamente mais perigoso, da segregação completa dos negros, meio escolhido pelos Estados U nidos, ou o método, embora mais lento, preferido pelos latinos, em geral, mais humano, mais inteligente, embora moralmente mais perigoso durante o perío do de transição, isto é, a fase mais ou menos prolongada, da eliminação do elemento negro pela miscigenação. (D uarte, 1947, p. 6)

Esse B rasil branco é também o Brasil da grande imigração do pós-Abolição, que teve em São Paulo o seu epicentro. N ão é por acaso que ainda nos dias de hoje essa ideologia se exprima de maneira mais livre e clara por ocasião do aniversário da cidade de São Paulo: 
Tudo por aqui foi construído pelo espírito empreendedor da iniciativa privada. $\mathrm{H}$ á quem atribua toda a pujança paulista ao café. I sso'é verdade, mas apenas em parte. Plantar café todos os Estados podiam. M as foi só em São Paulo que o café gerou riquezas. Por quê? Porque aqui havia imigração e isso, na verdade, explica tudo. 0 café era uma cultura nômade por natureza. Em poucos anos esgotava a fertilidade das terras e as plantações se deslocavam em busca de solos virgens. Em São Paulo não. 0 café, por aqui, se fixou graças aos conhecimentos de agricultura que os imigrantes trouxeram consigo. ( $\mathrm{N}$ eto, 2003)

Já para os militantes do M N U dos anos de 1980, que se perguntaram também "o que é o Brasil?", a resposta mais corrente foi a de um país multirracial, dominado por uma minoria branca, que explorava a maioria negra, a exemplo do que se passava na África austral:

Excetuando os índios, progressivamente exterminados, o africano escravo foi o primeiro e o único trabalhador do novo país. E durante três séculos e meio ergueu as estruturas econômicas deste gigante chamado Brasil. $\mathrm{N}$ as plantações de cana-de-açúcar, nos algodoais, na mineração de ouro, diamante e prata, nos cafezais, bem como em todos os demais elementos formadores da economia nacional, nutriram do suor e do sangue martirizado do negro escravo. 0 negro escravo será o próprio corpo e alma deste país. $M$ as a despeito dessa realidade histórica inegável e incontraditável, os africanos e seus descendentes nunca foram e não são tratados como iguais pelos segmentos minoritários brancos que completam o quadro democrático nacional. Esta minoria de ascendência européia tem mantido a exclusividade do poder, do bem-estar, e da renda nacional. (M N U , 1988, p. 53)

M as, quando se pergunta "quem é o povo brasileiro?" mudam também as respostas, independentemente da classe social de quem responde. O Brasil é "mestiço" tanto para Gilberto Freyre - muitas vezes tomado como intelectual orgânico da oligarquia proprietária (Genovese, 1988) -, como para M anuel Q uerino, cuja cor, origem e militância nos meios operários da Bahia são conhecidos; ou para um intelectual comunista de classe média como Jorge Amado. Para ficarmos em M anuel Q uerino (1980, p. 156):

Do convívio e colaboração das raças na feitura deste País, procede esse elemento mestiço de todos os matizes, donde essa plêiade ilustre de homens de talento que, no geral, representaram o que há de mais seleto nas afirmações do saber, verdadeiras glórias da nação.

Enquanto para intelectuais negros dos anos de 1950, como Guerreiro Ramos, Abdias do N ascimento, ou para um autor contemporâneo como Joel Rufino, o povo brasileiro é negro:

Explico-me: desde que se define o negro como um ingrediente normal da população do país, como povo brasileiro, carece de significação falar de 
problema do negro puramente econômico, destacado do problema geral das classes desfavorecidas ou do pauperismo. 0 negro é povo, no Brasil. $N$ ão é um componente estranho de nossa demografia. Ao contrário, é a sua mais importante matriz demográfica. E este fato tem de ser erigido à categoria de valor, como o exige a nossa dignidade e o nosso orgulho de povo independente. 0 negro no Brasil não é anedota, é um parâmetro da realidade nacional. A condição do negro no Brasil só é sociologicamente problemática em decorrência da alienação estética do próprio negro e da hipercorreção estética do branco brasileiro, ávido de identificação com o europeu. (Ramos, 1995, p. 200)

Acervo Fundação Biblioteca $\mathrm{N}$ acional
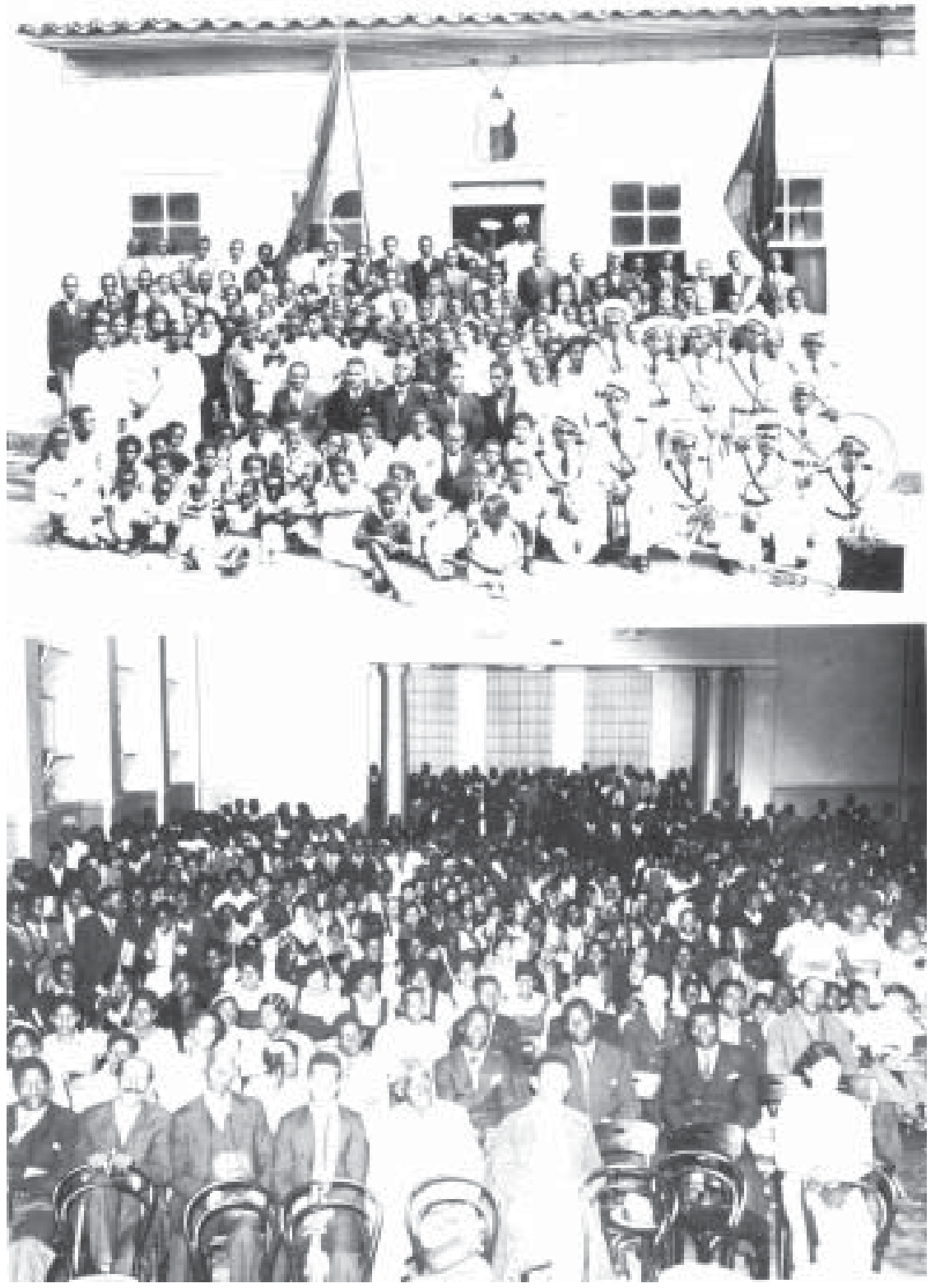

D elegação ao aniversário da Frente N egra Brasileira em 1935. 
Em resumo, a integração racial dos negros brasileiros deu-se também em diferentes contextos discursivos, que privilegiaram formas diversas de imaginar a nação brasileira - a nação branca, a nação multirracial, a nação mestiça e a nação negra. Com exceção da primeira dessas formas, repudiada por quase todos, não se pode dizer que os intelectuais negros preferiram especificamente qualquer uma das demais.

\section{À guisa de conclusão}

Vista em perspectiva histórica, a agen da política dos negros brasileiros nasce da luta contra as barreiras legais à promoção e à mobilidade social de pessoas de cor, desmanchadas ainda no período colonial, para chegar, nos anos de 1980, à reivindicação de igualdade de direitos sociais, ou seja, de acesso do povo brasileiro, negro, aos direitos da cidadania.

$\mathrm{No}$ abolicionismo, procurou-se extinguir quaisquer barreiras à igualdade formal de todos perante a lei, o que deveria permitir a ascensão social de pretos e mulatos, individualmente; enquanto nos anos de 1930, o combate ao preconceito de cor, exercido de modo informal, mas reiterado e difuso em todo o tecido social, transformou-se em bandeira de luta da FrenteN egra Brasileira, que enxergava a origem dessas discriminações e preconceitos no estado de despreparo moral da massa negra.

A partir dos anos de 1940, começa a ganhar corpo uma potente ideologia nacional que reúne os principais elementos dessa agenda histórica de lutas: a democracia racial. Como alinhei em outro texto (G uimarães, 2003), ainda que tal ideologia tenha sido desenvolvida por intelectuais brancos como Gilberto Freyre (1940) e Arthur Ramos (1943), ela ganhou rapidamente a adesão dos principais intelectuais negros mobilizados na luta anti-racista, como aqueles ligados ao jornal Quilombo. M ais que isto, como vimos na citação acima de Guerreiro Ramos, tais intelectuais modificaram o sentido freyreano da democracia racial o de uma matriz cultural híbrida em que a mestiçagem, tanto biológica, como cultural, diluía quase que naturalmente as diferenças sociais, políticas e culturais atreladas às raças humanas - para transformá-lo no ideal de igualdade política e cultural entre pessoas de cores e origens diversas, numa sociedade ainda dominada por valores estéticos inculcados pelo colonialismo português.

N os anos de 1950, Guerreiro Ramos funda uma nova ontologia política para o negro no Brasil, ao dizer que o povo brasileiro não é apenas mestiço, mas negro, não no sentido de uma raça, mas de um lugar, como aponta corretamente Joel Rufino (1995, p. 28):

Para Guerreiro Ramos, pois, negro não é uma raça, nem exatamente uma condição fenotípica, mas um topo lógico, instituído simultaneamente pela cor, pela cultura popular nacional, ela consciência da negritude como valor e pela estética social negra. U m indivíduo preto de qualquer classe, como também um mulato intelectual ou um branco nacionalista (por exemplo) podem ocupar esse lugar e dele, finalmente, visualizar o verdadeiro B rasil. 
Esse importante deslocamento de sentido é tributário, como espero ter sugerido, de uma longa tradição do pensamento social brasileiro negro, que tem como principais características: denunciar o isolamento moral e social dos negros, induzido pela estética e pela ciência européias; tratar os africanos como colonizadores do Brasil; entender o país como produto do trabalho negro; ver a classe trabalhadora brasileira como originária dos escravos africanos, dos artesãos e artistas negros e mestiços; entender a cultura e os costumes dos africanos como base de nossa cultura popular.

Tal matriz de pensamento é grandemente independente, como também espero ter sugerido, seja dos diferentes modos de integração dos negros, principalmente intelectuais, às elites sociais brasileiras, seja aos diferentes modos de pensar a nação brasileira - como mestiça, negra ou multirracial.

A partir da segunda metade dos anos de 1960, com o golpe de Estado e a repressão política, toda a mobilização negra passou a se fazer a partir da denúncia da "democracia racial" como um mito, ou seja, como refúgio discursivo das classes dirigentes e ideologia de dominação (Fernandes, 1965). M as tão forte e socialmente difusa era a idéia de democracia racial que mesmo o M ovimento N egro U nificado, nos anos de 1980, declarava ainda lutar por "uma autêntica democracia racial" (M NU, 1988).

Foi essa guinada à esquerda que possibilitou ao negro ser pensado pelo MNU dos anos de 1980 como povo oprimido e que a autêntica democracia racial fosse também uma luta contra a exploração capitalista. Tal maneira de compreen-der a opressão negra pode, então, ser incorporada tanto a ideologias políticas anticapitalistas (comunistas ou socialistas), quanto a ideologias liberais ou democráticas, que privilegiam apenas a luta pelos direitos civis. E m ambas, 0 negro é um lugar - o lugar do povo - que se opõe às elites, ou às classes dominantes- os brancos. E aqui aparece, de modo sub-reptício, a antiga oposição entre os que pensam o Brasil como branco e os que o pensam como negro ou mestiço.

N otas

1 Para efeito de simplificação nomeamos, no texto, os afro-descendentes pelo modo como eram comumente chamados, ou seja, "pretos", "negros" ou "mulatos"; do mesmo modo, um intelectual será considerado "branco" quando era assim tratado em seu tempo. A palavra "intelectuais", por seu turno, será usada no sentido de liderança moral, cultural e política, à maneira de Gramsci.

20 s estudos de "relações raciais" no Brasil começaram com D onald Pierson (1942), atingindo seu ápice nas décadas de 1950 e 1960 (Azevedo, 1953; Costa Pinto, 1953; Wagley, 1952; Bastide e Fernandes, 1955; N ogueira 1955; H arris 1956 ; H utchinson 1957; C ardoso e I anni, 1960; Fernandes, 1965). Sobre a diferença entre esses estudos 
e aqueles feitos anteriormente, principalmente por Gilberto Freyre e Arthur Ramos, ver Guimarães, 2004.

3 Analisou-se em maior detalhe tal trajetória em Guimarães, 2004a. Para uma análise mais aprofundada da imprensa negra paulista ver, entre outros, Bastide, 1983 e Ferrara, 1986.

4 Ver sobre a Frente N egra Brasileira: Fernandes, 1965; Pinto, 1993 e Barbosa, 1998.

5 Entre outras organizações, muito atuante no período foi também a U nião dosH omens deC or (Silva, 2003).

6 E screve Reis (1999, p. 34): “O s candomblés, desde cedo, procuraram atrair adeptos e clientes de grupos não-africanos, entre outras razões para formar um cinturão protetor, uma maior penetração e alguma legitimidade no seio da sociedade local. O s deuses africanos com freqüência guiaram seus devotos à revolta, mas fizeram suas carreiras em terra de branco principalmente ajudando-os a sobreviver - e melhor viver - no cotidiano".

\section{Bibliografia}

ANDRADE, Mário. "A superstição da cor". Boletim Luso-A fricano. Rio de Janeiro, dez. 1938.

AZEVEDO, Thales de. LesÉlites de couleur dans une ville brésilienne. Paris, U nesco, 1953.

BARBOSA, Márcio (org.). Frente N egra Brasileira: depoimentos. São Paulo, Quilombhoje, 1998.

BASTIDE, Roger. "The Present Status of Afro-American Research in L atin America" . Daedulus, n. 103, 1974, pp. 111-123. 1983.

. "A imprensa negra do Estado de São Paulo". EstudosA fro-brasileiros, São Paulo,

BASTIDE, Roger e FER N AN DES, Florestan. R elações raciaisentrenegrose brancosem São Paulo. São Paulo, U nesco/ Anhembi, 1955.

BUTLER, Kim. Freedoms Given, Freedoms Won. A fro-Brazilian in Post-A bolition São Paulo and Salvador. N ew Brunswick, N ew J ersey e L ondon, Rutgers U niversity Press, 1998.

CARDOSO, Fernando Henrique e IANNI, O ctavio. Cor e mobilidade social em Florianópol is, aspectos das relações entre negros e brancos numa comunidade do Brasil Meridional. São Paulo, Cia. Editora N acional, 1960.

COSTA PINTO, Luiz de Aguiar. O negro no R io de Janeiro: relações de raças numa sociedade em mudança. São Paulo, Companhia Editora N acional, 1953.

CRUZ E SOUZA, João de. "O emparedado". Obras, São Paulo, Cultura, 1943.

DEGLER, Carl N. N either Black nor White. M adison, U niv. of Wisconsin Press, 1991.

DU ARTE, Paulo. "N egros do Brasil". O Estado deS. Paulo, 16 abr. 1947, p. 5 e 17 abr. 1947, p. 6. 
FER N AN DES, Florestan. A integração do negro na soci edade de classes São Paulo, Cia Editora N acional, 2 vols., 1965.

. N egroin Brazilian society. Trad. JacquelineD. Skiles, A. Brunel, e Arthur R othwell.

Edited by Phyllis B. Eveleth. N ew York, Columbia U niversity Press, 1969.

FERRARA, M iriam N icolau. A imprensa negra paulista (1915-1963). São Paulo, FFLCH U SP, 1986.

FRAZIER, Franklin. "Some Aspects for Race Relations in Brazil". Phylon-R eview of R ace and C ulture, III , 3, 1942.

FREYRE, Gilberto. 0 mundo que o português criou. Rio de Janeiro, José Olympio, 1940.

GAM A, L uis. "Carta de L uis G ama a Lúcio de M endonça”. N ovosEstudos, n. 25, São Paulo, Cebrap, out. 1989.

GENEVOSE, Eugene D.The World the saveholders made, Wesleyan U niversity Press, 1969.

GU IM ARÃES, Antonio S. A. "D émocratie raciale". C ahiers du Brésil C ontemporain, Paris, n. 49-50, 2003, pp.11-38.

GUIM ARÃES, Antonio S. A. "O projeto U nesco na Bahia”. Comunicação ao Colóquio Internacional "O projeto U nesco no Brasil: uma vol ta crítica ao campo 50 anos depois", Centro de E studos Afro-O rientais da U niversidade Federal da Bahia, Salvador, Bahia, entre 12 e 14 jul. 2004.

H ARRIS, M arvin. "Race and Class", Town and C ountryin Brazil. N ew York, Columbia U niversity Press, 1956.

H UTCH IN SON , H arry W. Village and Plantation Lifein N or theastern Brazil. Seatle, U niversity of Washington Press, 1957.

LEITE, J osé C orreia. ...E disse o vel ho militanteJ oséC orreia Leite. São Paulo, Secretaria M unicipal de Cultura, 1992.

M ovimento N egro U nificado. 1978-1988, 10 anos de luta contra o racismo. Salvador, Confraria do Livro, 1988.

N ABU C O, Joaquim. O A bolicionismo. Rio de Janeiro, N ova Fronteira, 1999.

NETO, J oão M ellão. "Eu me orgulho de ser paulista". O Estado de S. Paulo, 24 jan. 2003.

N O GU EIRA, O racy. Preconceito demarca. A srelaçõesraciaisem I tapetiniga. São Paulo, Edusp, [1955] 1998.

PIERSON, Donald. N egroes in Brazil: A Study of Race Contact in Bahia. Chicago, U niversity of Chicago Press, 1942 (em português: Brancos e pretos na Bahia, São Paulo, Cia. Editora N acional, 1971).

PIN TO, Regina Pahim. O movimento negro em São Paulo: luta eidentidade. FFL CH U SP. São Paulo, 1993.

Q U ERINO, M anuel Raimundo. "O colono preto como fator da civilização brasileira”. Afro-Ásia, n. 13, 1980, pp. 143-158.

RAM OS, Arthur. Guerra erelações deraça. R io de J aneiro, Gráfica Perfecta, 1943. 
RAM OS, Alberto Guerreiro. I ntrodução crítica à sociologia brasileira. Rio de Janeiro, UFRJ, 1995.

REIS, J oão J osé. M emorial para concurso deProfessor Titular do D epartamento deH istória da U niversidade Federal da Bahia, Salvador, 1999.

RU FIN O, J oel. "O negro como lugar”. Em GU ERREIRO RAM OS, Alberto. I ntrodução Crítica à Sociologia Brasileira. Rio de Janeiro, Ed. U FRJ , 1995, pp. 19-30.

SILVA, Josenilda. "A U nião dos H omens de Cor: aspectos do movimento negro dos anos 40 e 50". Estudos A fro-A siáticos, ano 25, n. 2, 2003, pp. 215-236.

SPITZER, Leo. Livesin between: assimilation and marginality in A ustria, Brazil, West A frica, 1780-1945. Cambridge U niversity Press, Cambridge, 1989.

WAGLEY, Charles. R ace et classe dansleBrésil rural. Paris, U nesco, 1952.

REsumo - O AUTOR trata neste artigo de três questões: os diversos modos de integração dos "negros" à sociedade brasileira; a maneira também diversa como se formou a idéia de nação brasileira; e finalmente o papel ativo dos intelectuais "negros" na formação do que entendemos por "democracia racial" . O seu argumento é de que foram os intelectuais "negros" os responsáveis pela enorme abrangência e capilaridade da doutrina de "democracia racial" entre nós, que a transformou, durante muito tempo, em importante instrumento de mobilização política dos negros. Tal doutrina incorporou idéias elementares, dispersas ao longo da história brasileira, desenvolvidas principalmente por intelectuais "brancos", como J oaquim N abuco, Gilberto Freyre ou Arthur Ramos, mas re-trabalhadas e re-significadas por intelectuais negros, independentemente do modo como estes se integraram à sociedade brasileira e do modo como identificaram-se como nacionais.

Abastract - IN THIS article, the author deals with three issues: the various modes of integrating "blacks" into Brazilian society; the likewise diverse manners by which the idea of a Brazilian nation came about; and, finally, the active role of "black" intellectuals in forming what we understand as "racial democracy". H e argues that "black" intellectuals were responsible for the comprehensiveness and capillarity of the "racial democracy" doctrine amongst us, which for a long time was an important instrument for the political mobilization for blacks. This doctrine incorporated elementary ideas, dispersed throughout Brazilian history, that had been developed mainly by "white" intellectuals, such as J oaquim N abuco, Gilberto Freyre and Arthur Ramos, but were later reworked and re-signified by black intellectuals, regardless of how the latter came to be integrated into Brazilian society and how they identified themselves as nationals.

A ntonio Sérgi o A Ifredo Guimarãesé professor do D epartamento de Sociologia da U SP e autor, entre outros livros, de R acismo edi scriminação (N ovos Toques, 1998), R aci smo e anti-racismo no Brasil (Editora 34, 1999) e Classes, raças de democracia (E ditora 34, 2002).

Esse texto apóia-se em palestra feita pelo autor no C entre for Brazilian Studies, U niversity of 0 xford, em 28 de outubro de 2003, sob o mesmo título.

Texto recebido e aceito para publicação em 20 de fevereiro de 2004. 